\title{
ANL/ES/CP- -85936
}

\section{Development of Mercury Control Enhancements for Flue-Gas Cleanup Systems}



Work supported by the U.S. Department of Energy, Assistant Secretary for Fossil Energy, under contract W-31-109-ENG-38. 


\section{DISCLAIMER}

Portions of this document may be illegible in electronic image products. Images are produced from the best available original document. 


\title{
DEVELOPMENT OF MERCURY CONTROL ENHANCEMENTS FOR FLUE-GAS CLEANUP SYSTEMS
}

\author{
C. David Livengood \\ Hann S. Huang \\ Marshall $\mathrm{H}$. Mendelsohn \\ Jiann M. Wu \\ Argonne National Laboratory \\ 9700 South Cass Avenue \\ Argonne, Illinois 60439
}

\begin{abstract}
Combustion sources, including those using coal for fuel, contribute a significant fraction of total anthropogenic mercury emissions. Unfortunately, recent field studies have shown that current flue-gas cleanup (FGC) systems are relatively ineffective in controlling elemental mercury, which is a major component of the mercury emissions for many systems. Research at Argonne National Laboratory has been focused on techniques to enhance the capture of elemental mercury in existing FGC systems. For dry processes, these studies have included evaluation of the factors that control mercury capture by commercial activated carbons (both with and without chemical pretreatment), testing of novel proprietary sorbents under development by several firms, and investigation of sorbents based upon chemical pretreatment of low-cost mineral substrates. To enhance the ability of wet scrubbers to capture mercury, the studies have looked at the effects of improved mass transfer through both mechanical and chemical means, as well as the conversion of elemental mercury into more soluble species that can be easily absorbed.
\end{abstract}

\section{Introduction}

Title III of the Clean Air Act Amendments of 1990 focused attention on controlling emissions of hazardous air pollutants (HAPs). Among the listed HAPs, mercury emissions have been singled out as either the principal subject or a major component of three current EPA studies

Work supported by the U.S. Department of Energy, Assistant Secretary for Fossil Energy, under contract W-31-109-ENG-38. 
because of concerns over possibly serious effects on human health. Some of those emissions originate in the combustion of coal, which contains trace amounts of mercury. One estimate has placed total anthropogenic mercury emissions in the United States at about 250 tons/yr, with coal-fired utility boilers contributing about 59 tons/yr. Although individual facilities may not exceed the statutory "trigger" level for control of 10 tons/yr for a single HAP or 25 tons/yr for any combination of HAPs, control requirements could still be imposed since the limit can be lowered based on pollutant potency, persistence, bioaccumulation, or other factors.

For many HAPs, wet scrubbing and/or efficient collection of fly ash appear to offer adequate levels of control. However, data collected by the Department of Energy (DOE) and the Electric Power Research Institute (EPRI) at operating electric-power plants have shown that conventional FGC technologies are not very effective in controlling emissions of mercury in general, and are particularly poor at controlling emissions of elemental mercury. Since a significant fraction of the total mercury emissions at many sites is in the elemental form, enhancements or supplemental control technologies need to be developed. Coal preparation techniques may be able to remove some of the mercury before combustion, but postcombustion cleanup is likely to be needed as well.

This paper reviews research being conducted at Argonne National Laboratory on the capture of elemental mercury in flue gas by both dry sorbents and wet scrubbing. The emphasis in the research is on development of a better understanding of the key factors that control the capture of mercury. Future work is expected to utilize that information in the development of new or modified process concepts featuring enhanced mercury capture capabilities.

\section{Background}

Mercury emissions from coal combustion have been shown to vary considerably from site to site. It is well known that the chemical composition of coal is highly variable, even within a given seam. The concentration of mercury is no exception, as it exhibits variations that span several orders of magnitude. For example, a range in concentration from less than $0.01 \mathrm{ppm}$ up to $3.3 \mathrm{ppm}$ has been reported for bituminous coal, and values as high as $8.0 \mathrm{ppm}$ have been reported for subbituminous coal. ${ }^{1}$ Physical coal cleaning techniques can remove a significant fraction of the mercury before combustion, but the reductions are quite coalspecific and dependent upon the particular cleaning techniques chosen. ${ }^{2}$

The fate of trace elements in the combustion process is influenced by the type of boiler, the operating conditions, and the FGC system. Mercury belongs to a group of elements and compounds denoted as Class III, which remains primarily in the vapor phase within the boiler and subsequent FGC system. However, that state can be influenced by reactions with other elements, such as chlorine, and by fly-ash characteristics (e.g., unburned carbon) that affect adsorption processes. The concentration of mercury in the flue gas from typical coal combustors ranges from less than 10 to more than $50 \mu \mathrm{g} / \mathrm{Nm}^{3}$.

Until recently, few reliable data on mercury control have been available for FGC technologies used on coal-fired systems. Large variations in reported removals have been typical, due both 
to differences in coal and operating characteristics and to inaccuracies in sampling/analytical procedures. ${ }^{1}$ Better data are now becoming available as a result of extensive sampling campaigns for HAPs at a number of power plants under the sponsorship of the DOE Pittsburgh Energy Technology Center, as well as similar work carried out by the EPRI. These power plants were chosen so as to give a representative cross section of coals, boiler types, and control technologies. Significant variations in performance were still observed, with mercury removals in electrostatic precipitators (ESPs) ranging from about 15 to $75 \%$. Very limited data gave a range of removals for baghouses from 10 up to $70 \%$. Mercury removal measurements for wet flue-gas desulfurization (FGD) systems were also quite variable, with values ranging from near zero to about $50 \%{ }^{3}$

Much of the variation in removal performance may be caused by differences in the chemical form of the mercury in the flue gas. The presence of chlorine in coal means that mercury can be found in both the elemental $(\mathrm{Hg})$ and chloride $\left(\mathrm{HgCl}_{2}\right)$ species, with the relative amounts depending on such factors as the ratio of chlorine to mercury, the gas temperature, and the gas residence time at various temperatures. ${ }^{4}$ While other species are also possible and may be present in small amounts, these two appear to be the most significant for control considerations. The huge difference in solubility between the two species is particularly important in wet scrubbing applications.

Most available information on mercury control technologies for combustion sources has originated in work with waste incinerators. In such cases, activated carbon has been shown to be an effective sorbent for mercury. However, flue-gas conditions at incinerators are much different in temperature and composition from those found at coal-fired utility boilers, and the performance/economics of activated carbon can be expected to differ as well. In addition, the presence of wet FGD systems at many utility boilers presents a considerably different set of conditions and problems/opportunities that need to be considered.

Thus, there are multiple challenges that need to be addressed in the development of mercury control measures for coal-fired systems. These challenges include (but are not limited to) the:

- Low concentration of mercury in flue gas.

- Presence of mercury in the vapor phase.

- Multiple mercury species and variable speciation.

- Potential interactions of other flue-gas species with mercury and/or sorbents.

- Extremely low solubility of elemental mercury.

- Need to either recover captured mercury or dispose of it in a stable form.

\section{Research Program}

Based on Argonne's initial survey of published information, ${ }^{1}$ a number of sorbents and chemical additives with the potential for enhancing the capture of elemental mercury in dry or wet/dry FGC systems were selected for laboratory investigation. The study of dry sorbents was chosen for several reasons. Many existing coal-fired plants have only particulate-matter control, usually in the form of ESPs, and these could be well suited to duct- or furnaceinjection of mercury sorbents. Also, European experience with the addition of 
sorbents/chemicals to spray-dryer systems on municipal waste incinerators has indicated that greatly enhanced mercury removals are possible. Initial phases of this research focused on the performance of various activated carbons, ${ }^{5}$ while more recent work has investigated the potential of low-cost mineral substrates pretreated with several different chemical compounds. This line of research was developed in response to data from other tests showing that several thousand pounds of carbon could be required for every pound of mercury captured in a ductinjection control approach. The cost of activated carbon, plus questions regarding capture of the conductive carbon particles in an ESP, suggested that a low-cost, non-carbon-based sorbent material could be desirable.

In addition to the dry sorbent research, the presence of wet FGD systems at many power plants and industrial facilities has provided an impetus for investigation of mercury removal in wet scrubbing. The initial literature study found very little information regarding potential performance enhancements for scrubbers operating on coal-fired systems, although some work has been done for applications in other industries. ${ }^{6}$ To date, the research has focused on physical modifications designed to improve the absorption of mercury by the scrubber liquid, and on the testing of chemical agents selected for their potential to react with mercury. Oxidizing agents that can convert $\mathrm{Hg}$ into $\mathrm{HgCl}_{2}$ or another soluble species are readily available and several have been tested. However, reactions observed between the oxidizing agents and other flue-gas species could lead to high additive consumption and excessive process cost. Recent work has focused on a commercial oxidant formulation that appears to take advantage of a synergism between the removal reactions for different gas species, which leads to a degree of selectivity for mercury removal.

\section{Experimental Facilities}

Argonne's FGC-laboratory facilities include a fixed-bed reactor system for studying dry sorbents, a complete wet scrubber system, and a spray-dryer/fabric-filter system. Supporting facilities include a system that can provide known concentrations of elemental mercury in a gas stream, a gas-supply system capable of blending synthetic flue gas from bottled gases, online gas-analyzers, and data loggers. The following sections briefly describe the key systems. More detailed descriptions of all of the systems can be found in References 7 and 8 .

\section{Mercury Supply and Analysis}

The feed-gas preparation system consists of a mercury-containing permeation tube, a constanttemperature water bath, and a carrier-gas supply. The design capacity of the system is 20 $\mathrm{L} / \mathrm{min}$ of gas with mercury concentrations of up to $100 \mu \mathrm{g} / \mathrm{m}^{3}$. Mercury measurements are made using a gold-film mercury-vapor analyzer. The range of the instrument is 0 to $999 \mu \mathrm{g} / \mathrm{m}^{3}$ with a sensitivity of $3 \mu \mathrm{g} / \mathrm{m}^{3}$ and an accuracy of $\pm 5 \%$ at $100 \mu \mathrm{g} / \mathrm{m}^{3}$.

\section{Fixed-Bed Reactor}

The fixed-bed reactor vessel, which is constructed of glass, is $4 \mathrm{~cm}$ in diameter and $14 \mathrm{~cm}$ in height. A glass frit is positioned in the lower section to support materials placed inside the reactor. To avoid fluidization of the bed materials, the feed gas enters the reactor from the top 
and exits at the bottom. During shakedown and baseline tests, the reactor was packed with either silica sand $(120 \mathrm{~g})$ or a mixture of silica sand and hydrated lime $\left(\mathrm{Ca}(\mathrm{OH})_{2}\right)$ in a weight ratio of 40:1. The $\mathrm{Ca}(\mathrm{OH})_{2}$ has been employed because it is a common sorbent for sulfur dioxide $\left(\mathrm{SO}_{2}\right)$ in $\mathrm{FGC}$ systems. The large amount of sand is used to avoid channeling caused by lime agglomeration. For additive/sorbent testing, small amounts of material being studied are added to the sand/Ca(OH $)_{2}$ bed material. To maintain a uniform temperature during experiments, the reactor is immersed in a fluidized-bed, constant-temperature sand bath. To preheat the incoming feed gas to a temperature equal to that maintained in the fixed-bed reactor, the gas-transfer line is wrapped with heating tapes. A diagram of the reactor with the feed and analyzer systems is shown in Figure 1.

\section{Wet Scrubber}

Figure 2 presents a diagram of the wet scrubber system. All of the principal vessels are constructed of glass. The scrubber column has an inside diameter of $7.6 \mathrm{~cm}$ and an active height of nearly $53 \mathrm{~cm}$. It is normally operated in a countercurrent mode with the flue gas entering at the bottom. The scrubber is constructed of several interchangeable sections so that it can be configured as a flooded column (no internals), a four-stage disc and donut column, or an intermediate combination. For most of the experiments described here, the combination mode was used with the lower part of the column left open to accommodate packing. A modified lower section was also employed in some tests to investigate the effects of flue gas flowing over an agitated pool of liquid containing mercury-control additives. At the opposite extreme, the lower portion of the column was flooded with scrubber liquor for some tests by using a sieve plate in the bottom of the column to "hold up" some of the liquid. Varying the liquor recirculation rate between its limits of 330 and $1420 \mathrm{~mL} / \mathrm{min}$ produced the desired degree of flooding. The temperature of the scrubber liquor can be adjusted by heating the holding tank with heat tapes. The $\mathrm{pH}$ of the liquid in the holding tank is sampled continuously and can be adjusted either manually or automatically by adding reagent from a chemical feed tank.

\section{Experimental Results}

\section{Dry Sorbents}

Following initial shakedown tests that verified that neither the sand nor the lime in the fixed bed gave any measurable mercury removal, a variety of dry sorbents were studied. In addition to comparing the performance of different types of sorbents/additives, the research program has investigated the effects of varying process parameters, such as sorbent particle size, sorbent loading in the reactor, reactor/gas temperature, and mercury concentration. ${ }^{5,7}$ For most of the tests, the amounts of sorbent added ranged from 1 to $10 \mathrm{wt} \%$ (relative to the lime). Three fixed-bed reactor temperatures were evaluated: 55,70 , and $90^{\circ} \mathrm{C}$. Target mercury concentrations in the nitrogen feed gas of either 44 or $96 \mu \mathrm{g} / \mathrm{m}^{3}$ were used, and the feed-gas flow rate was fixed at $10 \mathrm{~L} / \mathrm{min}$.

Characteristics of some of the sorbents investigated thus far are given in Table 1. For the activated carbons, by far the best removal results were obtained with sample CB-II, which 
was commercially treated with about $15 \mathrm{wt} \%$ sulfur. The effects of both temperature and mercury concentration are explored in Figure 3 for this sorbent. The capacity is seen to increase strongly with decreasing temperature. The capacity of the carbon also increases with the concentration of mercury in the gas, indicating better utilization of the carbon with the greater driving force provided by the higher concentration. Another potentially significant trend is shown in Figure 4, where greater sorbent utilization is seen for smaller particles. This may indicate that for the larger particles not all of the available surface area is being "reached" by mercury present in the gas stream, but this phenomenon is still being studied since some of the variation may also be due to effects of the reactor design and sorbent loading.

The success of the sulfur-treated carbon is thought to be based on a combination of physical adsorption and chemical reactions that produce mercury sulfide. This suggests that chemical additives producing other compounds, such as mercury chloride, might also be beneficial for removal. To explore this possibility, another carbon sample $(\mathrm{AC})$, which previously gave essentially no removal, was treated with calcium chloride $\left(\mathrm{CaCl}_{2}\right)$ in the ratio of about $6: 1$ by weight. The treated carbon gave excellent removals and actually performed better than the sulfur-treated carbon.

Recently, the research on lower-cost alternatives to activated carbon has focused on several high-surface-area and/or low-cost mineral substrates listed in Table 1. Tests of the materials in the as-received condition gave moderate mercury removals for the molecular sieve sample and essentially no removals for pumice and vermiculite. In current research, the samples are being treated with chemical additives shown to be effective with activated carbon and tests are being run at various additive concentrations, mercury concentrations, and flue-gas temperatures. Figure 5 gives the results of experiments with volcanic pumice treated with $\mathrm{CaCl}_{2}$, potassium iodide $(\mathrm{KI})$, and sulfur. While the untreated pumice was ineffective for mercury removal, all of the treatments produced significant removals. At $70^{\circ} \mathrm{C}$, the sulfurtreated sorbent gave $100 \%$ removal for over an hour, while the iodide-impregnated sorbent gave $100 \%$ removal for a few minutes followed by a decrease in removal that appeared to level out at about $30 \%$. The chloride-impregnated sorbent behaved somewhat differently, with the removal gradually increasing to a final value of about $30 \%$.

As noted previously, flue-gas temperature has been shown to be a particularly important variable in mercury capture. In order to explore the effects of temperature on the treated sorbents, additional tests were run at a temperature of $150^{\circ} \mathrm{C}$. Figure 6 gives a comparison of the results at the two temperatures for the iodide- and sulfur-impregnated sorbents. The iodide-impregnated sample behaved very similarly at the two temperatures. However, the sulfur treatment that was so effective at the lower temperature was found to be totally ineffective at the higher temperature. This may be due to a change in the form of the sulfur, but this issue has not yet been resolved.

Other typical flue-gas species (e.g., $\mathrm{SO}_{2}$ ) may have an effect on mercury capture by some sorbents. To explore these possible effects, provision for adding $\mathrm{SO}_{2}$ or other gas species from the existing flue-gas blending system has been added to the fixed-bed system. Initial tests with activated carbon $\mathrm{CB}-\mathrm{II}$ and $\mathrm{SO}_{2}$ appear to show a slightly reduced absorption 
capacity, but these results are inconclusive at this time due to interference effects in the mercury analyzer. Further tests are planned.

\section{Wet Scrubbing}

Preliminary data from field-sampling campaigns have indicated that elemental mercury is not appreciably removed in typical wet-scrubber systems. This is not surprising given the very low solubility of mercury, even as compared to nitric oxide (NO), which is notably difficult to remove in a wet scrubber without some form of chemical enhancement (such as ferrous•EDTA addition). In previous research, Argonne's laboratory wet scrubber has demonstrated baseline removals of about $90 \%$ for $\mathrm{SO}_{2}$ and only 1-2\% for NO. Therefore, very little if any removal of mercury was anticipated.

Initial experiments were conducted using the scrubber as described above, no packing, and various degrees of "flooding" in the lower part of the column to promote gas-liquid contact. The scrubbing liquors tested were distilled water, a saturated $\mathrm{Ca}(\mathrm{OH})_{2}$ solution, and a $\mathrm{Ca}(\mathrm{OH})_{2}$ solution with $1000 \mathrm{ppm}$ of potassium polysulfide. The polysulfide has been claimed to promote mercury removal in other research. ${ }^{6}$ The mercury inlet concentration was about $40 \mu \mathrm{g} / \mathrm{m}^{3}$, the liquid height in the column was varied up to $43 \mathrm{~cm}$, and the temperature was varied between 22 and $50^{\circ} \mathrm{C}$. No mercury removal was detected under any of these conditions.

Next, 0.95-cm ceramic-saddle packing was added to the column and the inlet mercury concentration was increased to approximately $100 \mu \mathrm{g} / \mathrm{m}^{3}$ in order to more easily detect small amounts of removal. Sodium hydroxide $(\mathrm{NaOH})$ addition was used to control $\mathrm{pH}$ over a range of 5 to 12 . Removals of 3 to $5 \%$ were observed with distilled water over that range of $\mathrm{pH}$ values at $22^{\circ} \mathrm{C}$, and removals of 6 to $7 \%$ were obtained when the temperature was raised to $55^{\circ} \mathrm{C}$. However, tests involving polysulfide addition had to be terminated when reactions with the ceramic saddles produced hydrogen sulfide $\left(\mathrm{H}_{2} \mathrm{~S}\right)$ that interfered with the operation of the mercury analyzer.

In earlier research on mercury capture, stainless steel packing was found to promote mercury capture. ${ }^{6}$ Therefore, the ceramic saddles were replaced by $0.61-\mathrm{cm}$ stainless-steel packing, which gave the rather unexpected result of $11 \%$ removal with no liquid in the column. Removals with water in the column ranged from 15 to $20 \%$. Addition of polysulfide to the scrubber produced a noticeable increase in removal up to about $40 \%$. Since the polysulfide gave no measurable removals in water alone, it appears that there is a positive synergistic effect on removal involving the combination of polysulfide and stainless steel. It should be noted that this additive requires a very high $\mathrm{pH}$ to maintain its stability and this may preclude its use in most FGD systems.

In an effort to promote greater mercury capture through changing its chemical form, tests were conducted with several additives that combine strong oxidizing properties with relatively high vapor pressures. Tests with minimal gas-liquid contacting yielded mercury removals as high as $100 \%$, and indicated that the removal reactions were occurring in the gas phase above the scrubber liquor. However, tests with the addition of $\mathrm{SO}_{2}$ to the gas stream showed 
the additives to be very reactive with that species as well, which could result in excessively high additive consumption in order to realize effective mercury control.

Recently, tests have been conducted with a new combination of oxidizing chemicals, NOXSORB ${ }^{\mathrm{TM}}$, which is a product of the Olin Corporation. Typical feed-gas compositions have included $1000 \mathrm{ppm} \mathrm{SO}_{2}, 200 \mathrm{ppm}$ nitric oxide (NO), 15\% carbon dioxide $\left(\mathrm{CO}_{2}\right)$, and 33 $\mu \mathrm{g} / \mathrm{m}^{3} \mathrm{Hg}$. The flow rates were $25 \mathrm{~L} / \mathrm{min}$ for the feed gas and $500 \mathrm{~mL} / \mathrm{min}$ for the scrubber solution. While interferences from the additional gas species continue to be an issue in the operation of the mercury analyzer, the readings have indicated very good removal of elemental mercury. Figure 7 shows removal data for $\mathrm{Hg}, \mathrm{SO}_{2}$, and $\mathrm{NO}$ from a batch test with a dilute $(4 \%)$ solution of the as-received NOXSORB ${ }^{\mathrm{TM}}$ concentrate. An outlet reading of zero was obtained for $\mathrm{Hg}$ over a period of about $24 \mathrm{~min}$. During that period, the NO outlet concentration decreased rapidly to near zero and then rose gradually to where it was almost equal to the inlet value. The breakthrough in the $\mathrm{Hg}$ concentration (the point at which the concentration rises above zero) appeared to coincide with the point at which the NO concentration leveled off. The apparent correlation between $\mathrm{NO}$ and $\mathrm{Hg}$ removals from this and other tests may imply that the mercury is reacting with a product or intermediate of the $\mathrm{NO}$ removal process. A moderate degree of $\mathrm{SO}_{2}$ removal was also observed during the time the NOXSORB ${ }^{\mathrm{TM}}$ solution was circulating.

Another test involved a steady rate of addition of diluted NOXSORB ${ }^{\mathrm{TM}}$ solution to the scrubber. The NO removal stabilized at about $65 \%$ and remained at that level until termination of the addition. A similar behavior was observed for the $\mathrm{SO}_{2}$ concentration, which stabilized at approximately $45 \%$ removal. The $\mathrm{Hg}$ outlet readings remained at zero throughout the test until approximately $18 \mathrm{~min}$ after the addition was terminated. Further tests of this combined control technique are continuing.

\section{Conclusions}

The results and conclusions to date from the Argonne research on dry sorbents can be summarized as follows:

- Lime hydrates, either regular or high-surface-area, are not effective in removing elemental mercury.

- Mercury removals are enhanced by the addition of activated carbon.

- Mercury removals with activated carbon decrease with increasing temperature, larger particle size, and decreasing mercury concentration in the gas.

- Chemical pretreatment (e.g., with sulfur, $\mathrm{CaCl}_{2}$, or $\mathrm{KI}$ ) can greatly increase the removal capacity of activated carbon.

- Chemically treated mineral substrates have the potential to be developed into effective and economical mercury sorbents. 
- Sorbents treated with different chemicals respond in significantly different ways to changes in flue-gas temperature.

Preliminary results from the wet scrubbing research include:

- No removal of elemental mercury is obtained under normal scrubber operating conditions.

- Mercury removal can be improved by the addition of packing or other techniques to increase the gas-liquid contact area.

- Stainless steel packing appears to have beneficial properties for mercury removal. A synergism between stainless steel and polysulfide solutions has been observed.

- Oxidizing additives may be used in conjunction with wet scrubbing to greatly enhance removals. Synergisms between the removals of different flue-gas species may yield the selectivity required to avoid excessive additive consumption.

\section{Acknowledgments}

The authors gratefully acknowledge the guidance and support for this research provided by Perry Bergman, Charles Schmidt, and Charles Drummond of the Pittsburgh Energy Technology Center. Appreciation is also extended to Sherman Smith for his many contributions to the laboratory operations.

\section{References}

1. Huang, H.S., C.D. Livengood, and S. Zaromb, 1991, Emissions of Airborne Toxics from Coal-Fired Boilers: Mercury, Argonne National Laboratory report ANL/ESD/TM-35.

2. Toole-O'Neil, B., and D. Akers, 1995, Precombustion Control of Air Toxics, presentation at The Economic \& Environmental Aspects of Coal Utilization VI, The Engineering Foundation, Santa Barbara, Calif., Jan. 29 - Feb. 3.

3. Schmidt, C.E., and T.D. Brown, 1994, Results from the Department of Energy's Assessment of Air Toxics Emissions from Coal-Fired Power Plants, presentation at Illinois Coal Development Board Program Committee Meeting, Nov. 15.

4. Huang, H.S., J.M. Wu, and C.D. Livengood, 1995, Development of Dry Control Technology for Emissions of Mercury in Flue Gas, Proc. The Fourth International Congress on Toxic Combustion Byproducts, Berkeley, Calif. June 5-7.

5. Livengood, C.D., H.S. Huang, and J. M. Wu, 1994, Experimental Evaluation of Sorbents for the Capture of Mercury in Flue Gases, Proc. 87th Annual Meeting \& Exhibition of the Air \& Waste Management Association, Cincinnati, Ohio, June 19-24. 
6. Yan, T.Y., 1991, Reaction of Trace Mercury in Natural Gas with Dilute Polysulfide Solutions in a Packed Column, Industrial \& Engineering Chemistry Research, 30(12):2592-2595.

7. Livengood, C.D., M.H. Mendelsohn, H.S. Huang, and J.M. Wu, 1995, Development of Mercury Control Techniques for Utility Boilers, Proc. 88th Annual Meeting \& Exhibition of the Air \& Waste Management Association, San Antonio, Texas, June 18-23.

8. Mendelsohn, M.H., and J.B.L. Harkness, 1991, Enhanced Flue-Gas Denitrification Using Ferrous EDTA and a Polyphenolic Compound in an Aqueous Scrubber System, Energy \& Fuels, 5(2):244-247.

Table 1

Characteristics of Candidate Sorbents

\begin{tabular}{|c|c|c|c|c|}
\hline Sorbent & $\begin{array}{l}\operatorname{Cost}^{\mathrm{a}} \\
(\$ / \mathrm{lb})\end{array}$ & $\begin{array}{c}\text { Surface } \\
\text { Area } \\
\left(\mathrm{m}^{2} / \mathrm{g}\right)\end{array}$ & $\begin{array}{c}\text { Bulk Density } \\
\left(\mathrm{g} / \mathrm{cm}^{3}\right)\end{array}$ & $\begin{array}{c}\text { Median } \\
\text { Particle Size } \\
\quad(\mu \mathrm{m})\end{array}$ \\
\hline $\mathrm{AC}^{\mathrm{b}}$ & 0.50 & 1000 & 0.54 & $2000-2500^{c}$ \\
\hline WPL $^{b}$ & 0.50 & 894 & 0.57 & $2000-2500^{c}$ \\
\hline PC- $100^{b}$ & 0.50 & 965 & 0.52 & $2000-2500^{c}$ \\
\hline $\begin{array}{c}\mathrm{CB}-\mathrm{II}^{\mathrm{b}} \\
\text { (sulfur-treated) }\end{array}$ & 3.90 & 1050 & 0.56 & $2000-2500^{c}$ \\
\hline Molecular Sieve & 8.00 & 645 & 0.52 & 3.8 \\
\hline Vermiculite & 0.13 & 12.9 & 0.18 & 580 \\
\hline Pumice & 0.10 & 8.2 & 1.23 & 21 \\
\hline
\end{tabular}

Approximate - variable lot size

${ }^{\mathrm{b}}$ Activated carbon

${ }^{\circ}$ Commercial specifications - samples ground to less than $100 \mu \mathrm{m}$ for tests 

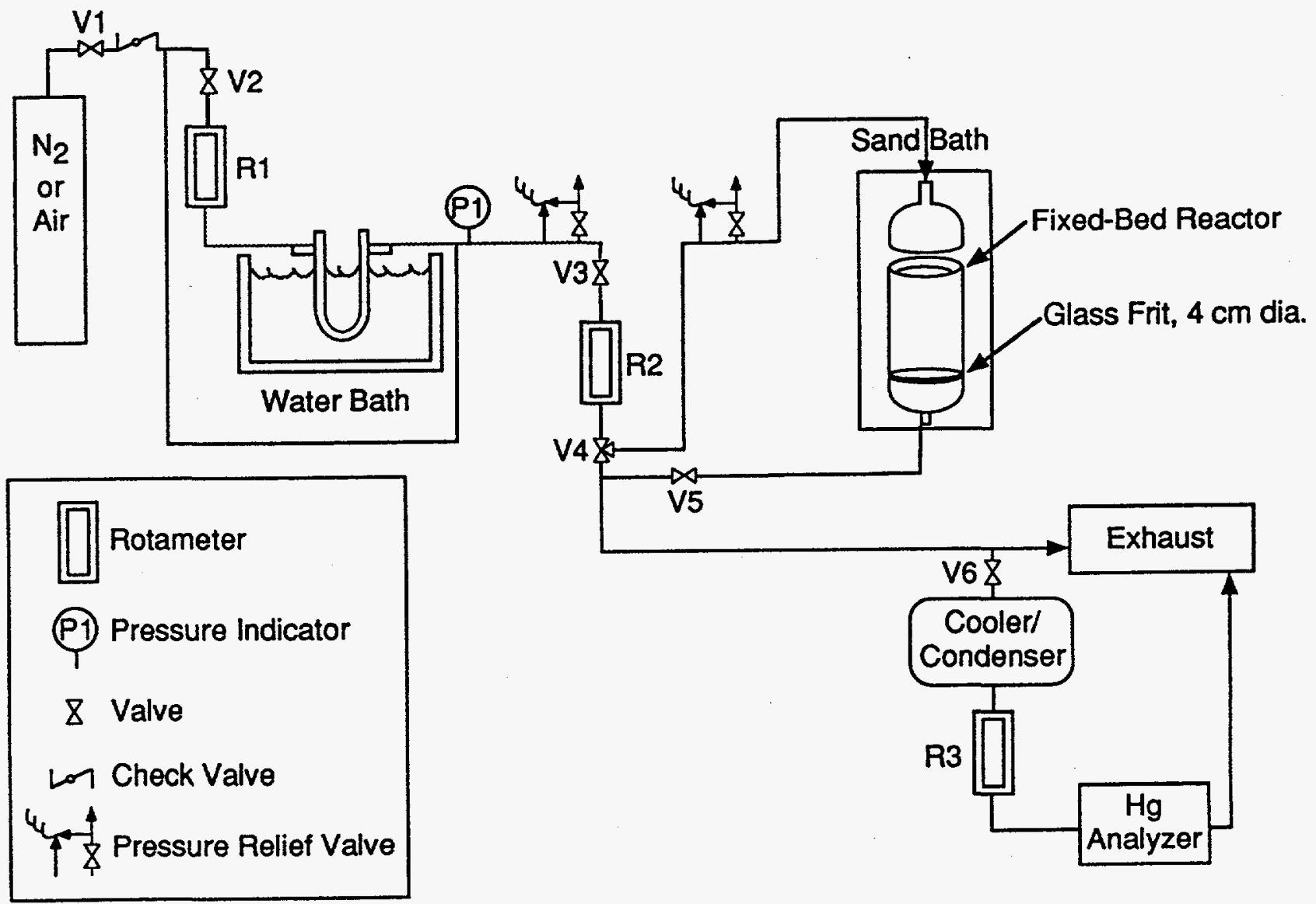

Figure 1

Fixed-bed Reactor Facility Diagram 


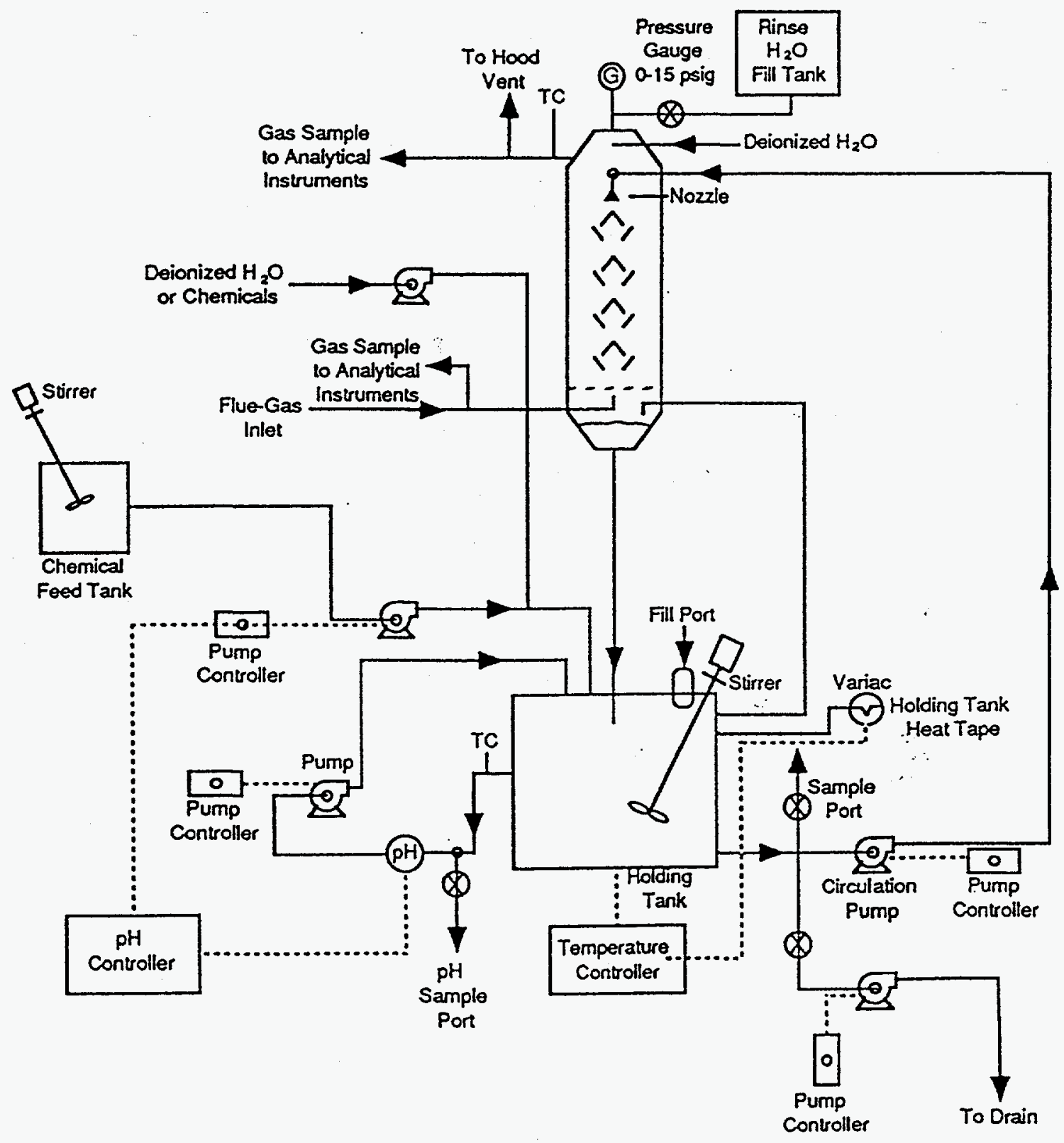

Figure 2

Wet Scrubber System Diagram 
Reactor Loading - Silica Sand/Ca $(\mathrm{OH})_{2} /$ Carbon CB-1I =

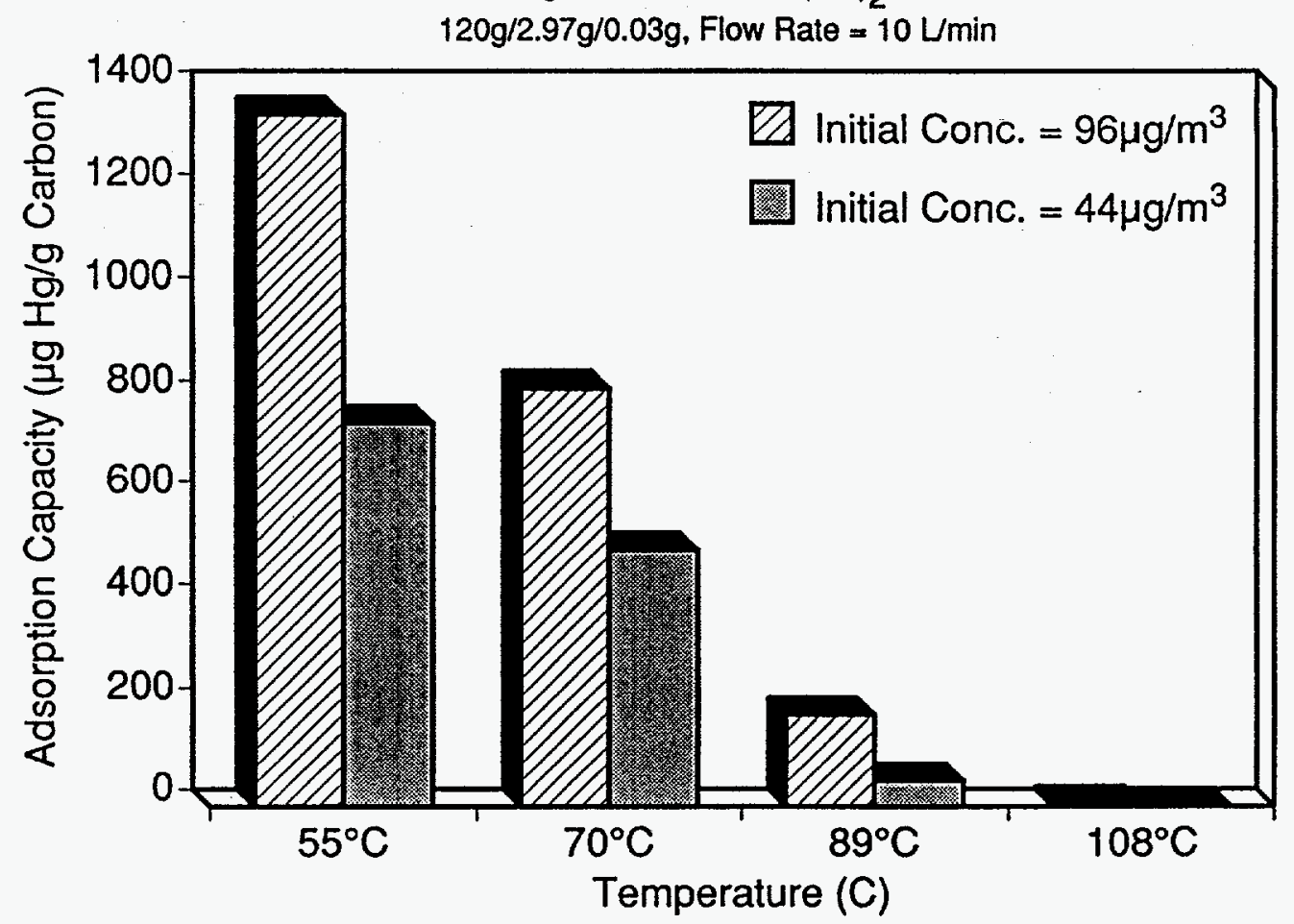

Figure 3

Effects of Temperature and Mercury Concentration on Removal Capacity of a Sulfur-Treated Activated Carbon

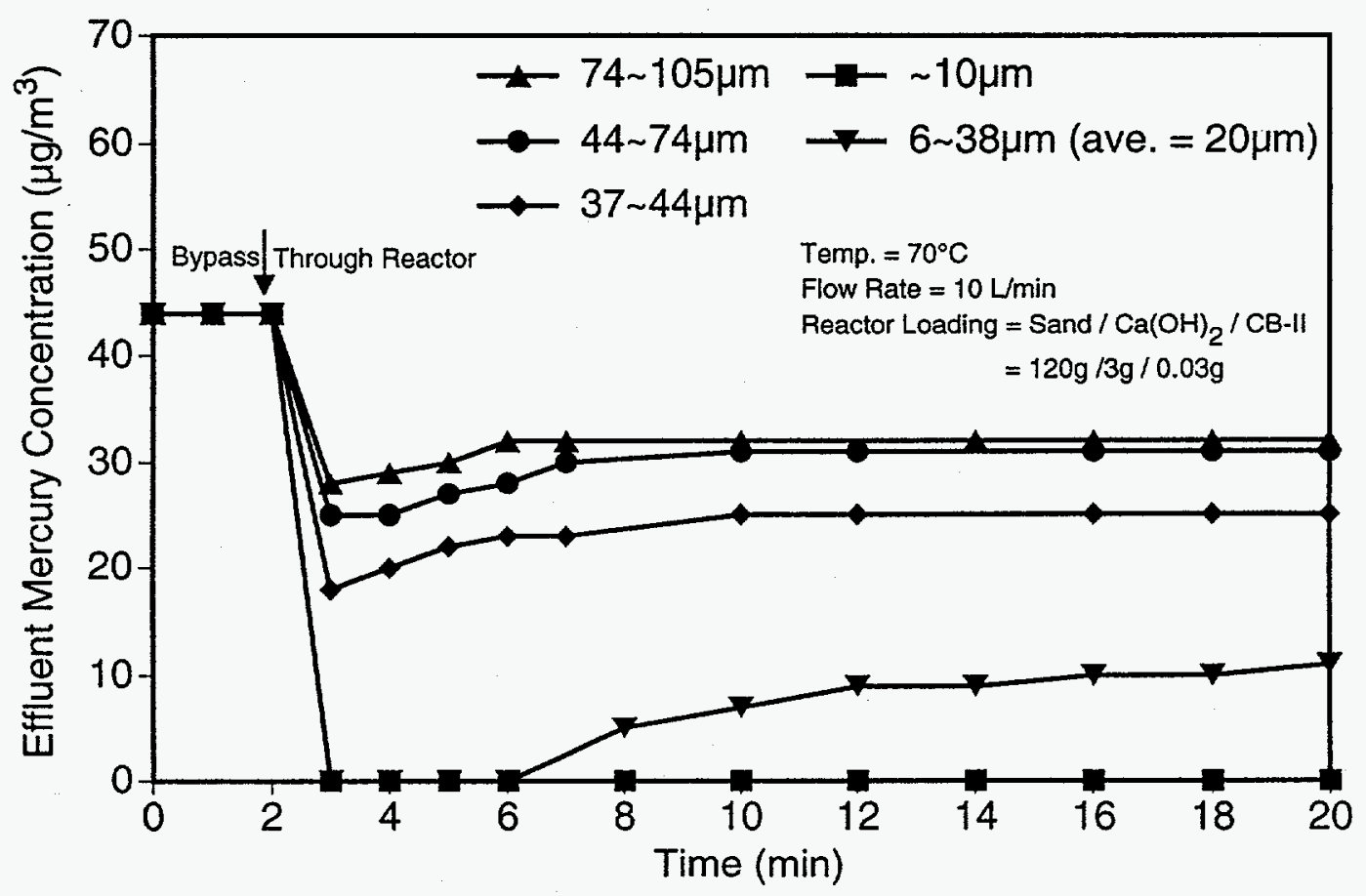

Figure 4

Effects of Activated Carbon Particle Size on Mercury Removal 




Figure 5

Effects of Chemical Pretreatment on an Inert Substrate at $70^{\circ} \mathrm{C}$

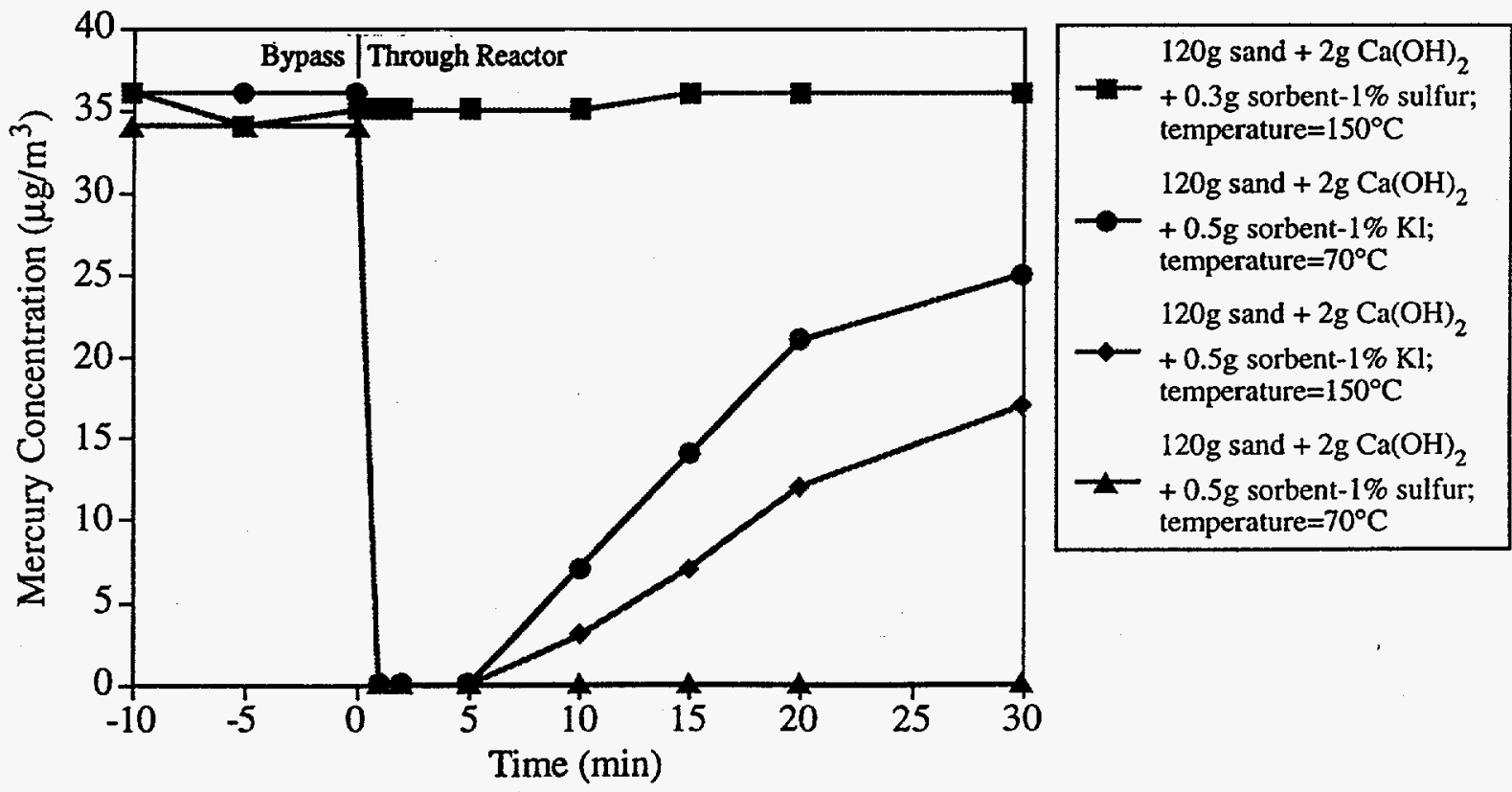

Figure 6

Effects of Different Temperatures on a Chemically Pretreated Inert Substrate 




Figure 7

Removals of $\mathrm{Hg}$, NO, and $\mathrm{SO}_{2}$ in the Wet Scrubber with a $4 \%$ NOXSORB ${ }^{\mathrm{TM}}$ Solution 